\title{
Mosquitos Dendrícolas (Diptera, Culicidae) em Internódios de Taquara da Floresta Atlântica, Serra do Mar e do Primeiro Planalto, Paraná, Brasil.
}

\author{
Ana Leuch Lozovei \\ Departamento de Patologia Básica, Setor de Ciências Biológicas da Universidade Federal do Paraná, \\ Jardim das Américas, Centro Politécnico, 81531-990, Caixa Postal 19031, Curitiba, Paraná, Brasil.
}

\begin{abstract}
During two consecutive years, from january 1985 to december 1986, studies were carried out on mosquitoes living in the internodes of bamboo in two distinct regions, the Atlantic Forest of the Serra do Mar and the First Plateau, both in the state of Paraná, Brazil. These dendricolous habitats are very different from other recorded mosquito breeding sites. The internodes of the green, living bamboo are closed reservoirs of water with only some small, lateral holes made by boring insects Eucalyptra barbara Schaus, 1894 and Eucalyptra fumida Schaus, 1894 (Lepidoptera, Noctuidae), and other animals. The water in the internodes derives from the bamboo itself. These are the first observations of this breeding behavior. Some females entirely enter the hole to oviposit while others dont't. Similar, artificially constructed habitats were studied at the same time by producing transvere openings and introducing water into the reservoir. Seventeen species of dendricolous mosquitoes were observed utilizing this unique habitat. Additional studies have elaborated other behavioral aspects of these mosquitoes.
\end{abstract}

Key words: bamboo, Culicidae, dendricolous mosquitoes, Diptera, ecology.

Palavras-chave: Culicidae, Diptera, ecologia, mosquitos dendrícolas, taquara.

\section{INTRODUÇÃO}

Mosquitos proliferam nos mais diversificados tipos de biótopos, uns formados com apreciáveis volumes de água, outros, com pequenos e até diminutos. A natureza dos substratos onde se acumula água para formar criadouros é bastante variada. A maioria predominante de criadouros na natureza têm como substrato básico o solo. Sobre o solo formam-se diversos tipos de criadouros constituídos por diferentes substratos de interferência humana ou não. Os formados por artefatos antrópicos são resultantes de produtos industrializados e abandonados na natureza após o uso, tais como pneus de veículos e recipientes de diversas substâncias, como latas, garrafas de vidro, de plástico e similares. Há ainda outros biótopos naturais cujos substratos, por serem de tecidos de determinadas plantas, diferem em muito dos anteriores. São os que têm por substrato o tecido das folhas, como as de bromeliáceas ou brácteas imbricadas onde se acumula água da chuva que em contato com o tecido foliar, formam-se os chamados criadouros fitotélmicos (gr. phytón = vegetal, planta). Outros, existem os formados em substrato lenhoso (xilema, o tronco), donde vem a denominação de biótopos dendrotélmicos ou dendrotelmatas (gr. déndron = árvore, lenho). Nesta categoria incluem-se os biótopos formados por internódios de taquaras e bambus e por ocos de diferentes tipos de árvores.

Taquara e bambu são nomes populares de determinados gêneros de plantas da família Gramineae ou Poaceae. São autóctones das regiões tropicais e subtropicais do globo terrestre. Dentre as gramíneas, os agrostologistas estudaram com destaque as taquaras e os bambus desde o século XIX (por volta de 1830). Nestes estudos, evidência foi dada a aspectos biológicos, morfológicos, citogenéticos e taxonômicos. O bambu 
mereceu ênfase por ser utilizado nas construções, na indústria de móveis, em produtos de decoração e, inclusive, na culinária com o aproveitamento do broto, especialmente na cozinha chinesa, VIRKKI (1963), McClure (1973), Soderstrom \& Calderón (1979), Calderón \& Soderstrom (1980).

Neste trabalho, as taquaras do gênero Merostachys sp, que conta com 25 espécies dispersas na área da América Central até a Argentina (Smith et al. 1981), são objeto de estudo para conferir sua importância em Entomologia relacionada com a procriação de mosquitos no interior de seus internódios. Quando os colmos de taquara atingem seu ciclo vegetativo pleno, no interior dos internódios acumula-se água resultante de seu próprio metabolismo. Trata-se da água metabólica que apresenta composição química diferente da água continental. Convém ressaltar que, para ocorrer procriação de populações de mosquitos em internódios de colmos verdes, são necessárias certas condições básicas, como internódios dotados de um ou mais furos laterais que sirvam de porta de entrada para as fêmeas oviporem e que contenham água em seu interior.

Existem, no Brasil e no exterior, algumas investigações utilizando internódios instalados experimentalmente com água adicionada. Entre os que recentemente investigaram esse tipo de habitat, estão Gomes et al. (1992) e Lopes (1997). Existe, também, alguma literatura sobre ocos de árvores, que são biótopos similares quanto à natureza do substrato aquático. Entre os que investigaram esse tipo de habitat, estão Gomes et al. (1992). Em diversas partes do mundo, trabalhos desta natureza foram elaborados com internódios instalados, como os de Mogi \& Suzuki (1983), Amerasinghe \& Alagoda (1984) e em ocos de árvores os desenvolvidos por Bradshaw \& Holzapfel (1984, 1988, 1991, 1992), Hard (1989), Juliano (1989), Copeland \& Craig (1990a, 1990b, 1992), Walker et al. (1991) e Juliano \& Reminger (1992).
$\mathrm{Na}$ presente investigação, propôs-se contribuir ao conhecimento sobre a bionomia de mosquitos que selecionam criadouros cuja água, em contato com o lenho dos colmos, cria condições completamente diferentes dos criadouros estabelecidos no solo. Objetivou-se, em especial, verificar quais espécies de mosquitos para procriar-se selecionam os criadouros em internódios de taquara in natura e em internódios instalados experimentalmente, como também analisar as peculiaridades destes habitats.

\section{MATERIAL E MÉTODOS}

$\mathrm{O}$ presente trabalho foi realizado em criadouros dendrotélmicos (internódios de taquara) em dois locais distintos. O primeiro, na Floresta Atlântica, Serra do Mar, no Parque Estadual Pico do Marumbi, na altura do km 32 da Estrada da Graciosa, no município de Quatro Barras (Lat. S 2519'55"; Long. W 4854'35"; Alt. 974 m). $\mathrm{O}$ segundo, no Primeiro Planalto Paranaense, situa-se em mata preservada da Estância Hidromineral Ouro Fino, no município de Campo Largo (Lat. S 25¹9'28"; Long. W 49²9'13"; Alt. 822m).

O Parque Estadual Pico do Marumbi, criado pelo Decreto $\mathrm{n}^{\circ} 5599$ de 04.10 .78 pelo Governo do Estado do Paraná, com extensão de 367,84 mil ha fica entre o Mar e o Primeiro Planalto. Foi criado com objetivos de preservar a Floresta Atlântica, de evitar o assoreamento da Baía de Paranaguá e de proteger os mananciais de muitos rios e riachos que abastecem de água potável as cidades litorâneas $\mathrm{e}$ algumas da Região Metropolitana de Curitiba. Ao longo da mata na Serra do Mar, dentro do Parque Marumbi, existe taquaral autóctone em constante renovação de seu ciclo vegetativo. 
A Estância Hidromineral Ouro Fino* foi fundada aos 23 de abril de 1946. Consta de uma extensão de 960 ha com flora e fauna preservadas e de um parque ecológico que ocupa um milhão de metros quadrados com equipamentos de lazer, que protege a fonte de água mineral Ouro Fino. Nesta mata, também existe taquaral autóctone em constante renovação (A Fonte, 1996).

Em ambos os locais, foram investigados criadouros de mosquitos formados por internódios verdes de taquara enfileirados em estratos verticais de zero a 15 metros de altura, inseridos em colmos vivos que apresentavam furos laterais de diferentes padrões: circulares ou quadrados e retangulares, de dimensões diminutas ou não. Como termo de comparação com biótopos de internódios verdes, foram estudados, também, internódios individuais com corte transversal numa das extremidades, instalados experimentalmente em cinco estratos verticais, especificamente para obter amostras de formas imaturas de mosquitos. Este procedimento foi adotado nos dois locais de pesquisa.

Os colmos verdes de taquara eram cortados rente ao chão com serra de cortar ferro, tendo o cuidado de mantê-los eretos para não desperdiçar a água contida em seu interior. Abria-se, então, os internódios um a um, a partir do nível do solo. Praticava-se o corte transversal na parte superior de cada internódio e recolhia-se todo o líquido junto com detritos $\mathrm{e}$ sedimento, se houvesse, em recipientes de polietileno de $300 \mathrm{ml}$ com tampa. Em caso de haver sedimento espesso, esse era lavado com água destilada para recolher todo o conteúdo disponível.

Durante o período de estudo, abateu-se um total de 240 colmos verdes, sendo 120 na Serra do Mar e outros 120 no Primeiro Planalto, com alturas totais que variavam de 5 a $15 \mathrm{~m}$. Para não sobrecarregar as atividades de campo e do laboratório, em

\footnotetext{
* Propriedade particular da Família Mocelin
}

cada local derrubavam-se mensalmente cinco colmos verdes ao longo de 24 meses de estudo. Cada colmo de taquara fornecia número variável de internódios dependendo de sua altura.

Nas fichas, para cada colmo abatido atribuía-se um número de ordem seqüencial. Os internódios eram identificados por estrato com a respectiva altura, com o volume de água contendo ou não mosquitos imaturos e com presença ou não de detritos. Ao mesmo tempo que se anotavam a quantidade e os padrões de furos laterais existentes com suas dimensões e formas características, verificava-se, também, a temperatura do ambiente e a da água, assim como o $\mathrm{pH}$ da água no interior dos internódios.

Para obter amostras de mosquitos imaturos em internódios instalados de taquara, convencionou-se utilizar todos de tamanho e diâmetro idênticos ou pelo menos aproximados e com mesmo volume de água. Eram abastecidos com água comum do rio na Serra do Mar e com água mineral (pois não havia outra) no Primeiro Planalto. Foram distribuídos por estratos de zero a 4 $\mathrm{m}$ de altura $(0 \mathrm{~m}, 1 \mathrm{~m}, 2 \mathrm{~m}, 3 \mathrm{~m}, 4 \mathrm{~m})$, presos com fio de arame em varas de taquaras ou em galhos de árvores. Em cada estrato armavam-se cinco internódios por mês, perfazendo um total de 25 internódios. Portanto, para as amostras de culicídeos mensalmente colhidas, em ambos os locais, somavam-se um total de 50 internódios, 25 para cada local de coleta, totalizando $600 \mathrm{em}$ cada um. Por ocasião destas coletas, as amostras eram acondicionadas em recipientes de polietileno de $300 \mathrm{ml}$ com tampa, devidamente identificados, como no procedimento para os internódios de colmos verdes. Todos os meses, os internódios esvaziados eram novamente preenchidos de água e suspensos nos respectivos estratos, e assim sucessivamente. $\mathrm{O}$ 
trabalho foi desenvolvido de janeiro de 1985 a dezembro de 1986.

No laboratório, as amostras de mosquitos trazidas do campo eram tratadas da seguinte maneira: a) cada semana procedia-se a contagem do número de exemplares de cada espécie por estágio (ovos, os quatro ínstares larvares e pupais); b) as pupas eram separadas individualmente para obter adultos, assim como as larvas, pois as populações compreendiam ou não predadoras e/ou canibais, cuja identificação era feita pelos quartos ínstares larvares e confirmada pelos adultos obtidos.

Para a identificação específica de mosquitos e atualização da posição taxonômica de alguns gêneros seguiu-se a literatura de Rozeboon \& Komp (1950), Lane \& WHITMAN (1951), LANE (1953a, 1953b), FORATTINI (1965, 1975), VALÊNCIA (1973), KNIGHT \& STONE (1977, 1978), ZAVORTINK (1979) E HARBACH (1991, 1994).

\section{RESULTADOS E DISCUSSÃO}

Os 240 colmos de taquara verde, de altura variável, abatidos em ambas as localidades, forneceram um total de 3.752 internódios. $\mathrm{Na}$ Serra do Mar, os 120 colmos de alturas entre 8 e $15 \mathrm{~m}$ forneceram 2.160 (57,57\%) internódios, enquanto os 120 colmos do Primeiro Planalto, também de alturas variadas entre 5 e $8 \mathrm{~m}$, totalizaram 1.592 $(42,43 \%)$ internódios (Tabela I).

Os internódios sem água, num total de 1.236, distribuíram-se com $814(65,86 \%)$ na Serra do Mar e 422 (34,14\%) no Primeiro Planalto (Tabela I). Um total de 988 internódios, mesmo com água, não contiveram formas imaturas de mosquitos, perfazendo 24,19\% na Serra do Mar e $75,81 \%$ no Primeiro Planalto (Tabela I). Já dos 1.528 internódios com formas imaturas de mosquitos, $72,45 \%$ coube ao Parque Marumbi na Serra do Mar, enquanto 27,55\%, ao Primeiro Planalto (Tabela I).

Tabela I. Total de internódios de taquara pesquisados em duas localidades estudadas, Serra do Mar (Quatro Barras) e Primeiro Planalto (Campo Largo), Paraná, Brasil, (jan.1985 a dez. 1986).

\begin{tabular}{|c|c|c|c|c|c|c|}
\hline \multirow{2}{*}{$\begin{array}{l}\text { Variáveis } \\
\text { Percentagem** }\end{array}$} & \multicolumn{2}{|c|}{ Serra do Mar (Quatro Barras) } & \multirow{2}{*}{$\begin{array}{l}\text { Prim.Planalto } \\
\text { Intern. verdes* (N1) }\end{array}$} & \multirow{2}{*}{$\begin{array}{l}\text { (CampoLargo) } \\
\text { Intern. inst. (N2) }\end{array}$} & \multicolumn{2}{|c|}{ Somatória } \\
\hline & Intern.verdes* (N1) & Intern. inst. (N2) & & & N1 & $\mathrm{N} 2$ \\
\hline Total de internódios & 2160 & 600 & 1592 & 600 & 3752 & 1200 \\
\hline Percentagem $* *$ & 57,57 & 50,0 & 42,43 & 50,0 & 100,0 & 100,0 \\
\hline Número de mosquitos & 6154 & 2489 & 1216 & 2490 & 7370 & 4979 \\
\hline Percentagem** & 83,50 & 49,99 & 16,50 & 50,01 & & \\
\hline Internódios sem água & 814 & 20 & 422 & 12 & 1236 & 32 \\
\hline Percentagem** & 65,86 & 62,50 & 34,14 & 37,50 & $32,94 \bullet$ & $2,67 \bullet$ \\
\hline Inter.s/água e s/mosq. & 239 & 150 & 749 & 224 & 988 & 374 \\
\hline Percentagem** & 24,19 & 40,11 & 75,81 & 59,89 & $26,33 \bullet$ & $31,16 \bullet$ \\
\hline Intern. c/ mosquitos & 1107 & 430 & 421 & 364 & 1528 & 794 \\
\hline Percentagem** & 72,45 & 54,16 & 27,55 & 45,84 & $40,73 \bullet$ & $66,17 \bullet$ \\
\hline
\end{tabular}

$\mathrm{Na}$ Serra do Mar, os colmos apresentaram crescimento muito desenvolvido fornecendo internódios em mais ou menos $25 \%$ mais longos, de diâmetro maior e com maior volume de água em seu interior. No Primeiro Planalto, ao contrário, os colmos tiveram alturas menores e, em conseqüência, os internódios eram mais curtos, com menor diâmetro e volume de água reduzido. Estas diferenças podem ter favorecido uma maior positividade para mosquitos em internódios na Serra do Mar. 
Com relação ao número de formas imaturas de culicídeos, mostrou-se diretamente proporcional ao espaço físico e ao volume de água, devido às peculiaridades específicas destas espécies dendrícolas. Trata-se de populações que têm comportamentos e exigências alimentares distintos, uma vez que são espécies predadoras, entomófagas e algumas, canibais. Por esta razão, o sucesso de procriação destas populações, nestes habitats, depende do grande espaço físico e de determinados volumes de água para que as larvas tenham condições de fugir às perseguições de inimigos. Estas condições são melhor preenchidas pelos internódios verdes, especialmente os da Serra do Mar, por serem recipientes mais amplos que os do Primeiro Planalto e, por conseguinte, mais eficientes para a procriação das populações em questão. Isto confirmou-se comparando ambas as localidades. Na Serra do Mar, proporcionalmente, é que se encontrou maior número de exemplares por internódio verde $(5,56)$, enquanto foram 2,89, no Primeiro Planalto. (Tabela I).

Quanto aos internódios instalados em estratos verticais, nas duas localidades, estes somaram um total de 1.200 unidades, sendo 600 em cada local (Tabela I). Na Serra do Mar, 430 internódios $(54,16 \%)$ apresentaram-se positivos para culicídeos, $150(40,11 \%)$ sem eles e $20(62,50 \%)$ sem água. No Primeiro Planalto, 364 (45,84\%) internódios contiveram mosquitos, 224 $(59,89 \%)$ apareceram sem mosquitos e 12 $(37,50 \%)$, secos (Tabela I). Neste tipo de criadouros, as condições físico-biológicas para a procriação são semelhantes, pois os internódios contêm aberturas transversais amplas e praticamente iguais em comprimento, diâmetro e volume de água e ainda em número de unidades exatamente igual. Na Serra do Mar, os 430 internódios contiveram 2.489 (49,99\%) exemplares de mosquitos, enquanto no Primeiro Planalto os 364 internódios, $2.490 \quad(50,01 \%)$ mosquitos (Tabela I). Levando-se em conta o número de internódios positivos para culicídeos em cada local, resultou uma média de 6,84 mosquitos de forma imatura por internódio no Primeiro Planalto e 5,79, na Serra do Mar. Comparando, porém, as duas localidades e os dois tipos de habitats juntos, os internódios verdes da Serra do Mar foram os que contaram com maior número absoluto de espécimes (Tabela I).

A interdependência desta fauna dendrícola e a retenção da água nos internódios de taquara favoreceram a formação de criadouros de mosquitos isolados do meio ambiente em pequenos canudos (internódios), interessantes e peculiares, únicos do gênero na natureza. São criadouros semipermanentes distribuídos em diversos estratos verticais como "bolsões verticais" fixos no solo, que também oferecem condições para outras espécies de insetos ali proliferarem.

Tanto em internódios com água límpida, dotados de furos laterais, circulares, diminutos (de 2 a $5 \mathrm{~mm}$ de diâmetro), como em águas turvas em internódios com furos quadrados ou retangulares (de 8x8 a até $15 \times 25 \mathrm{~mm}$ ), houve procriação de diversas espécies de mosquitos e, inclusive, de outra fauna associada. Evidentemente, cada espécie de mosquitos selecionou seus internódios preferenciais, com água límpida ou turva, com furos diminutos ou maiores, em maior ou menor altura, conforme suas exigências bionômicas. São populações com características bionômicas próprias, que para adentrar os internódios servem-se de furos elaborados por outra fauna silvícola. Estes biótopos dendrotélmicos englobam populações de diferentes exigências alimentares e nutricionais: fitófagos, bacteriófagos, entomófagos e canibais que coabitam sintopicamente ou não.

Os internódios de taquara com água funcionam como criadouros de culicídeos só quando contiverem alguma abertura que dê acesso ao seu interior, que pode ser um corte transversal provocado pela interferência humana ou furo produzido pela interferência de fauna silvícola. Em internódios verdes de colmos vivos, 
encontrou-se dois tipos (padrões) de furos produzidos pela fauna silvestre: circulares e quadrados/retangulares. Um dos responsáveis pela formação de furos circulares é o inseto da família Noctuidae, subfamília Ophederinae com duas espécies Eucalyptra babara e Eucalyptra fumida. Estes insetos evoluem no interior dos internódios vivos enquanto ainda fazem parte de colmos em pé, foi o que se observou nesta pesquisa. $\mathrm{O}$ acesso destes insetos aos internódios e a saída de seu interior processa-se através de furos por eles mesmos elaborados. Na mata, existe, ainda, uma outra fauna que também produz outros padrões de furos, quadrados ou retangulares, mais amplos que os anteriores. Não se conseguiu, porém, flagrar interveniente algum.

No conjunto, nas duas localidades de estudo, constatou-se um total de 17 espécies de mosquitos dendrícolas. Destas populações, em ambos os locais indistintamente, observou-se seis espécies nos dois tipos de internódios, verdes e instalados, (N1 e N2). Outras cinco espécies apareceram somente em internódios verdes, enquanto duas, só em internódios instalados nos dois locais e mais duas espécies em internódios instalados na Serra do Mar e, por último, uma, em internódios verdes, também, na Serra do Mar. Uma única espécie deste conjunto de populações foi encontrada em ambos os tipos de internódios na Serra do Mar e ainda em internódios instalados no Primeiro Planalto (Tabela II). Na Serra do Mar, foram constatadas todas as 17 espécies nos dois tipos de habitat. Já no Primeiro Planalto, constatou-se a presença de 14 espécies do total de populações registradas nestes habitats. Referindo-se à abundância destas populações, percebe-se claramente que algumas espécies ocorreram em número elevado, outras, em médio e outras, ainda, em cifras insignificantes. Como fator determinante deve ser levada em consideração a convivência de populações complexas de mosquitos de hábitos

Tabela II. Estudo comparativo da ocorrência de mosquitos em internódios de taquara verde (N1) e em internódios instalados (N2), Serra do Mar, (Quatro Barras) e Primeiro Planalto, (Campo Largo), Paraná, Brasil, (janeiro de 1985 a dezembro de 1986).

\begin{tabular}{|c|c|c|c|c|c|c|}
\hline \multirow[t]{2}{*}{ Espécies } & \multicolumn{2}{|c|}{ Serra do Mar } & \multicolumn{2}{|c|}{ Prim.Planalto } & \multicolumn{2}{|c|}{ Somatória } \\
\hline & N1 & $\mathrm{N} 2$ & N1 & $\mathrm{N} 2$ & N1 & $\mathbf{N} 2$ \\
\hline Culex (Carrollia) iridescens (Lutz, 1905) & 0 & 109 & 0 & 9 & $\mathbf{0}$ & 118 \\
\hline Culex (Carrollia) kompi Valencia, 1973 & 0 & 33 & 0 & 0 & $\mathbf{0}$ & 33 \\
\hline Culex (Carrollia) soperi Antunes \& Lane, 1937 & 29 & 0 & 6 & 0 & 35 & $\mathbf{0}$ \\
\hline Culex (Microculex) elongatus Rozeboom \& Komp, 1950 & 0 & 23 & 0 & 0 & $\mathbf{0}$ & 23 \\
\hline Culex (Microculex) neglectus Lutz, 1904 & 23 & 0 & 8 & 0 & 31 & $\mathbf{0}$ \\
\hline Sabethes (Peytonulus) aurescens* (Lutz, 1905) & 1703 & 159 & 318 & 9 & 2021 & 168 \\
\hline Sabethes (Sabethes) batesi Lane \& Cerqueira, 1942 & 26 & 0 & 0 & 0 & 26 & $\mathbf{0}$ \\
\hline Sabethes (Sabethinus) melanonynphe* (Dyar, 1924) & 248 & 0 & 111 & 0 & 359 & $\mathbf{0}$ \\
\hline Shannoniana fluviatilis (Theobald, 1903) & 156 & 869 & 88 & 465 & 244 & 1334 \\
\hline Trichoprosopon compressum* (Dyar \& Knab, 1907) & 19 & 227 & 15 & 136 & 34 & 363 \\
\hline Trichoprosopon pallidiventer* (Lutz, 1905) & 329 & 949 & 16 & 1833 & 345 & 2782 \\
\hline Trichoprosopon soaresi* Lane \& Cerqueira, 1942 & 0 & 9 & 0 & 10 & $\mathbf{0}$ & 19 \\
\hline Toxorhynchites (Lynchiella) bambusicola* (Lutz \& Neiva, 1913) & 925 & 0 & 368 & 0 & 1293 & $\mathbf{0}$ \\
\hline Toxorhynchites (Lynchiella) pusillus* (Costa Lima, 1931) & 22 & 0 & 230 & 0 & 252 & $\mathbf{0}$ \\
\hline Wyeomyia )Dendromyia) personata (Lutz, 1904) & 1122 & 42 & 0 & 61 & 1122 & 48 \\
\hline Wyeomyia (Wyeomyia) limai Lane \& Cerqueira, 1942 & 1075 & 40 & 36 & 181 & 1111 & 58 \\
\hline Wyeomyia (Wyeomyia) lutzi (Costa Lima, 1930) & 477 & 29 & 20 & 4 & 497 & 33 \\
\hline Total & 6154 & 2489 & 1216 & 2490 & 7370 & 4979 \\
\hline
\end{tabular}

\footnotetext{
* Larvas predadoras.
} 


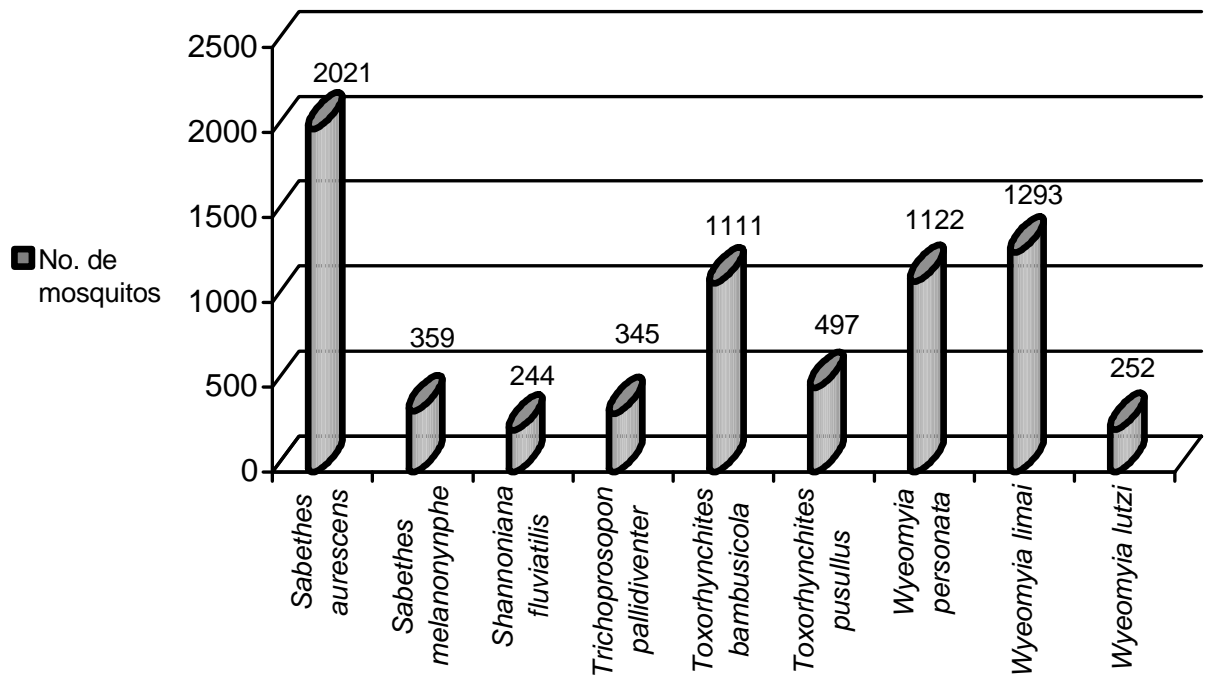

Figura 1. Espécies de mosquitos dendrícolas, em internódios verdes (N1), ocorrência acima de 100 exemplares, soma da Serra do Mar e do Primeiro Planalto.

predadores e/ou canibais, além das exigências biológicas específicas de cada espécie. Entre as espécies mais abundantes (de 100 em diante) em internódios de taquara verde (N1), figuram as espécies Sabethes aurescens, Sabethes melanonynphe, Shannoniana fluviatilis, Trichoprosopon pallidiventer, Toxorhynchites bambusicola, Toxorhynchites pusillus, Wyeomyia personata, Wyeomyia limai e Wyeomyia lutzi (Tabela II, Figura 1). Em internódios instalados individualmente, esta abundância evidencia-se pelas espécies Culex iridescens, Sabethes aurescens, Shannoniana fluviatilis, Trichoprosopon compressum e Trichoprosopon pallidiventer (Tabela II). Entretanto, duas espécies (Sabethes aurescens e Trichoprosopon pallidiventer) foram abundantes, esta em internódios instalados experimentalmente, aquela, em verdes vivos. Estas espécies demonstraram maior adaptabilidade às diferentes características existentes nos criadouros. Sabethes aurescens, porém, foi a espécie que ocorreu com maior número em internódios verdes (2.021), enquanto a Trichoprosopon pallidiventer, em internódios instalados (2.782) (Tabela II). Estas duas espécies, embora apresentem ecletismo quanto aos habitats estudados, cada qual tem preferências peculiares o que lhes possibilita desenvolvimento melhor. Uma ocorre em internódios verdes, outra, em internódios instalados. A água de internódios verdes, vivos, normalmente é límpida, sem sedimento, de odor agradável com pH oscilando entre 3,50 e 7,0, ou seja, de bem ácido a neutro. $O$ mesmo não acontece em internódios experimentais por serem dotados de ampla abertura contendo diversos detritos, fragmentos animais e vegetais, alguns da própria planta, outros carreados por diversas espécies de fauna que prolifera ou que freqüenta estes habitats. Este sapropel torna a água turva e de odor ligeiramente desagradável devido à decomposição da matéria orgânica. Seu pH oscila entre 5,00 e 7,15, de levemente ácido a levemente alcalino.

No clima tropical do Brasil, alguns pesquisadores constataram várias espécies de mosquitos procriando-se em internódios de bambu instalados experimentalmente e em ocos de árvores. Entretanto, a literatura é escassa no que se refere a mosquitos proliferando em internódios de taquara verdes, vivos, que ainda fazem parte integrante do ciclo vegetativo de colmos. GOMES et al. (1992) pesquisaram mosquitos em internódios instalados de bambu e em ocos de árvores no Vale do Ribeira, São Paulo, nas zonas rural, ruralurbana e urbana e confirmaram a existência de sete espécies. De todas, somente Culex 
iridescens (Lutz) coincide com a presente investigação uma vez que também foi encontrada em internódios instalados de taquara nas duas localidades. Entre as espécies por eles citadas, consta também Toxorhynchites sp, porém, só identificaram a nível de gênero. Lopes (1997), no Norte do Paraná, em mata ciliar ao longo de um ribeirão, estudou mosquitos que proliferam em internódios instalados de bambu e relacionou nove espécies nestes habitats. Das nove espécies encontradas, somente duas coincidem com o presente estudo: Trichoprosopon compressum e Trichoprosopon pallidiventer, que ocorreram tanto em internódios experimentais como em verdes nos dois locais de pesquisa.

Pesquisas em internódios instalados de bambu foram efetuadas em Sri Lanka, na República da Ásia ao Sul da Índia, Região Oriental, onde Amerasinghe \& Alagoda (1984) investigaram a procriação de culicídeos nestes habitats e relacionaram sete espécies de mosquitos. Nenhuma das espécies citadas, porém, coincide com o presente trabalho. A distância geográfica que separa as localidades investigadas e as condições ambientais talvez justifiquem a não coincidência entre a distribuição das espécies, mas demonstra que em qualquer região os culicídeos têm capacidade adaptativa para estes habitats. Em Nagasaki, Japão, Mogi \& Suzuki (1983) também pesquisaram em internódios instalados de bambu em que ocorreram duas espécies de culicídeos, a Topomyia yanbarensis Miyagi e a Tripteroides bambusa bambusa (Yamada), espécies de Região Paleártica..

\section{REFERÊNCIAS BIBLIOGRÁFICAS}

A FONTE, Boletim Informativo interno Empresa de Águas Ouro Fino Ltda, n. 5, 1996.

Amerasinghe, F. P. \& Alagoda, T. S. B. Mosquito oviposition in bamboo traps, with special reference to Aedes albopictus, Aedes novalbopictus and Armigeres subalbatus. Insect. Sci. Applic., v. 5, n. 6, p. 493-500. 1984.
Bradshaw, W. E. \& Holzapfel, C. M. Seasonal development of tree-hole mosquitoes (Diptera: Culicidae) and Chaoborids in relation to weather and predation. $\mathbf{J}$. Med. Entomol. v. 21, n. 4, p.366-378, 1984.

Bradshaw, W. E. \& Holzapfel, C. M. Drought and the organization of treehole mosquito communities.

Oecologia, v. 74, n. 4, p. 507-514, 1988.

Bradshaw, W. E. \& Holzapfel, C. M. Fitness and habitat segregation of British treehole mosquitoes in nature. Oecologia, v. 90, p. 227-237, 1991.

Calderón, C. E. \& Soderstrom, T. R. The Genera of Bambusoideae (Poaceae) of the America Continent: Keys and Comments. Smithsonian Contributions to Botany, n. 44, Smithsonian Institution Press, Washington, 1980, $27 \mathrm{p}$.

Copeland, R. S. \& Craig Jr, G. B. Cold hardiness of tree-hole mosquitoes in the Great Lakes region of the United States. Can. J. Zool., v. 68, p. 1307-1314, 1990a.

Copeland, R. S. \& Craig Jr, G. B. Habitat segregation among treehole mosquitoes (Diptera: Culicidae) in the Great Lakes region of the United States. Ann. Entomol. Soc. Am., v. 83, n. 6, p.10631073, 1990b.

Copeland, R. S. \& Craig Jr, G. B. Interspecific competition, parasitism, and predation affect development of Aedes hendersoni and A. triseriatus (Diptera: Culicidae) in artificial treeholes.

Ann. Entomol. Soc. Am., v. 85, n. 2, p. 154-163, 1992.

Forattini, O. P. Entomologia Médica, v. IV, Univ. São Paulo, São Paulo, 1965, 416 p.

Forattini, O. P. Entomologia Médica, v. II, Univ. São Paulo, São Paulo, 1975, 506 p.

Gomes, A. C.; Forattini, O. P.; Kakitani, I.; Marques, G. R. A. M.; Marques, C. C. A.;

Maruci, D. \& Brito, M. Microhabitats de Aedes albopictus (Skuse) na região do Vale do Paraíba, Estado de São Paulo, Brasil. Rev. Saúde Pública, v. 26, n. 2, p. 108-118. 1992. Harbach, R. E. A new subgenus of the genus Sabethes (Diptera: Culicidae). Mosq. Syst. v. 23, n 1, p. 1-9, 1991.

Harbach, R. E. The subgenus Sabethinus of Sabethes (Diptera: Culicidae). Syst. Entomol. , v. 19, n. 3, p. 207-234, 1994. 
Hard, J. J.; Bradshaw, W. E. \& MALARKEY, D. J. Resource - and density - dependent

devenlopment in tree-hole mosquitoes. Oikos, v. 54, p. 137-144, 1989.

Juliano, S. A. Geographic variation in vulnerability to predation and starvation in larval treehole

mosquitoes. Oikos, v. 56, p. 99-109, 1989.

Juliano, S. A. \& Reminger, L. The relationships between vulnerability to predation and behavior

of larval treehole mosquitoes: geographic and ontogenetic differences. Oikos, v. 63, n. 3, p. 465-476, 1992.

Knight, K. L. \& Stone, A. A Catalog of the Mosquitoes of the World (Diptera, Culicidae).

2 ed. Maryland. Entom. Soc. of America, 1977, 611 p.

Khight, K. L. \& Stone, A. Supplement to A Catalog of the Mosquitoes (Diptera, Culicidae).

Maryland. Entom. Soc. of America, 1978, 107 p.

Lane, J. \& Whitman, L. The subgenus Microculex in Brazil (Diptera: Culicidae).

Rev. Bras.

Biol., v. 1, n. 8, p. 341-366, 1951.

Lane, J. Neotropical Culicidae. v. I, Univ. São Paulo, São Paulo, 1953a, 548 p.

Lane, J. Neotropical Culicidae. v. II, Univ. São Paulo, São Paulo, 1953b, 1112 p.

Lopes, J. Ecologia de mosquitos (Diptera, Culicidae) em criadouros naturais $e$ artificiais de área rural do Norte do Estado do Paraná, Brasil. V. Coleta de larvas em recipientes artificiais instalados em mata ciliar. Rev. Saúde Pública São Paulo, v. 31, n. 4, p. 370-377, 1997.

Mcclure, F. A. Genera of bamboo native to the New World (Gramineae: Bambusoideae). Smithsonian Contributions to the Botany, v.9, Smithsonian Institution Press, Washington, 1973, 148 p.

Mogi, M. \& Suzuki, H. The biotic community in the water-filled internode of bamboos in Nagasaki, Japan, with special reference to mosquito ecology. Jap. J. Ecol. v. 33, n. 3, p. 271-279, 1983.
Rozeboon, L. E. \& Komp, P. W. A new Microculex elongatus from Colombia with notes on the

subgenus (Diptera: Culicidae). Proc. Ent. Soc. Wash., v. 52, n. 3, p. 147-157, 1950.

Sinsko, M. J. \& Grimstad, P. R. Habitat separation by differential vertical oviposition of

two treehole Aedes in Indiana. Environ. Entomol. v. 6, n. 3, p. 485-487, 1975.

Smith, L. B.; Wasshausen, D. C. \& Klein, R. M. Gramíneas. Gêneros: 1. Bambusa até 44. Chloris. Flora Ilustrada Catarinense, I Parte, Fascículo: As Plantas Gramíneas, 436 p. 99 estampas e 86 mapas. Itajaí, S.C. 1981.

Soderstrom, T. R. \& Calderón, C. E. Arberella (Poaceae: Bambusoideae): A new genus from Tropical America. Brittonia, v. 31, n. 4, p. 433-445, 1979.

Valencia, J. D. Mosquito studies (Diptera: Culicidae). XXXI. A revision of the subgenus

Carrollia of Culex. Contr. Amer. Ent. Institute, v. 9, n. 4, p. 1-134, 1973.

Virkki, N. Eighteen chromosome pairs in an American Bamboo, Chusquea subtessellata Hitchc. Jour. Agricul. University Puerto Rico, v. 47, n. 2, p. 98-101, 1963.

Walker, E. D.; Lawson, D. L. \& Klug, M. J. Nutrient dynamics, bacterial populations, and mosquito productivity in tree hole ecosystems and microcosms. Ecology, v. 72, n. 5, p. 1529-1546, 1991.

Zavortink, T. J. Mosquito studies (Diptera: Culicidae). XXXV. The genus new Sabethine genus Johnbelkinia and a preliminary reclassification of the composite genus Trichoprosopon. Contrib. Am. Entomol. Inst. (Ann. Arbor.), v. 17, n. 1, p. 1-61, 1979.

Received: March 25, 1998; Revised: June 16, 1998; Accepted: November 30, 1998. 